\title{
Aspergillus parasiticus Communities Associated with Sugarcane in the Rio Grande Valley of Texas: Implications of Global Transport and Host Association Within Aspergillus Section Flavi
}

\author{
N. P. Garber and P. J. Cotty
}

First and second authors: School of Plant Sciences, and second author: United States Department of Agriculture-Agricultural Research Service and School of Plant Sciences, The University of Arizona, Tucson. Accepted for publication 1 November 2013

\begin{abstract}
Garber, N. P., and Cotty, P. J. 2014. Aspergillus parasiticus communities associated with sugarcane in the Rio Grande Valley of Texas: Implications of global transport and host association within Aspergillus section Flavi. Phytopathology 104:462-471.

In the Rio Grande Valley of Texas (RGV), values of maize and cottonseed crops are significantly reduced by aflatoxin contamination. Aflatoxin contamination of susceptible crops is the product of communities of aflatoxin producers and the average aflatoxin-producing potentials of these communities influence aflatoxin contamination risk. Cropping pattern influences community composition and, thereby, the epidemiology of aflatoxin contamination. In 2004, Aspergillus parasiticus was isolated from two fields previously cropped to sugarcane but not from 23 fields without recent history of sugarcane cultivation. In 2004 and 2005, A. parasiticus composed 18 to $36 \%$ of Aspergillus section Flavi resident in agricultural soils within sugarcane-producing counties. A. parasiticus was not detected in counties that do not produce sugarcane. Aspergillus section Flavi soil communities within sugarcane-producing counties

differed significantly dependent on sugarcane cropping history. Fields cropped to sugarcane within the previous 5 years had greater quantities of A. parasiticus (mean $=16 \mathrm{CFU} / \mathrm{g}$ ) than fields not cropped to sugarcane (mean $=0.1 \mathrm{CFU} / \mathrm{g})$. The percentage of Aspergillus section Flavi composed of $A$. parasiticus increased to $65 \%$ under continuous sugarcane cultivation and remained high the first season of rotation out of sugarcane. Section Flavi communities in fields rotated to non-sugarcane crops for 3 to 5 years were composed of $<5 \%$ A. parasiticus, and fields with no sugarcane history averaged only $0.2 \%$ A. parasiticus. The section Flavi community infecting RGV sugarcane stems ranged from $95 \%$ A. parasiticus in billets prepared for commercial planting to $52 \%$ A. parasiticus in hand-collected sugarcane stems. Vegetative compatibility assays and multilocus phylogenies verified that aflatoxin contamination of raw sugar was previously attributed to similar A. parasiticus in Japan. Association of closely related $A$. parasiticus genotypes with sugarcane produced in Japan and RGV, frequent infection of billets by these genotypes, and the ephemeral nature of A. parasiticus in RGV soils suggests global transport with sugarcane planting material.
\end{abstract}

In the Rio Grande Valley in South Texas (RGV), aflatoxin concentrations are the most important criterion dictating the marketability and value of locally produced cottonseed and maize $(66,89)$. Aflatoxin contamination is caused by several species in Aspergillus section Flavi (13) which vary widely both within and among species in capacity to synthesize these highly carcinogenic toxins $(5,24,27)$. Some species produce both $B$ and $G$ aflatoxins while others produce only B aflatoxins due to a $0.9-$ to $2-\mathrm{kb}$ deletion in the aflatoxin biosynthesis gene cluster $(25,72)$. Based on genetic, physiological, and cultural characteristics, these species can be subdivided into distinct morphotypes (17) and vegetative compatibility groups (VCGs) (4). Diverse species, strains, morphotypes, and VCGs exist in complex communities that vary widely in average aflatoxin-producing ability among regions and fields $(2,5,69,90)$. The average aflatoxin-producing potential of Aspergillus section Flavi communities is a central criterion dictating the potential for crop aflatoxin contamination (47). Aspergillus flavus and A. parasiticus are the fungi most associated with aflatoxin contamination (51). However, A. flavus isolates vary widely in aflatoxin production, with some isolates producing little or no aflatoxins. A. parasiticus typically produces more consistent and higher concentrations of aflatoxins $(22,88)$.

Corresponding author: P. J. Cotty; E-mail address: pjcotty@email.arizona.edu

http://dx.doi.org/10.1094/PHYTO-04-13-0108-R

This article is in the public domain and not copyrightable. It may be freely reprinted with customary crediting of the source. The American Phytopathological Society, 2014
Aflatoxin contamination may result from infection by aflatoxin-producing fungi both during crop development and after crop maturation $(17,76)$. Although it is clear that the aflatoxinproducing potential of fungal communities associated with crops influences the likelihood of aflatoxin contamination, little is known about interactions between community composition of aflatoxin-producing fungi and crop plant cultivation (16). A few studies suggest that compositions of Aspergillus communities in field soils are influenced by both current and preceding crops $(43,48,65)$.

A. parasiticus is an antagonist of sugarcane mealybugs in Hawaii, the Philippines, Australia, and Colombia $(23,31,87,93)$ and, in this context, this species has been repeatedly associated with sugarcane. In Japan, fungi morphologically intermediate but closely related to both A. parasiticus and A. flavus were isolated from sugarcane in connection with aflatoxin contamination of raw sugar $(54,80,82,83)$. Although the pink sugarcane mealybug is rarely observed in Texas $(61,62)$, the role of sugarcane production in shaping Aspergillus section Flavi communities has not been explored. In RGV, sugarcane fields neighbor those of cotton and maize, with typical agronomic practice cropping sugarcane for 3 to 5 years with a single yearly harvest. Cotton typically follows sugarcane cropping and alternates with maize or sorghum in the following seasons.

The current study evaluated influences of sugarcane cultivation in Texas on compositions of Aspergillus section Flavi communities. In addition, $A$. parasiticus isolates from Texas sugarcane fields were subjected to phylogenetic and vegetative compatibility 
analyses along with isolates from Asia and elsewhere in order to investigate sugarcane-associated $A$. parasiticus lineages. The results suggest association and distribution of a distinct lineage of A. parasiticus with sugarcane cultivation in both Asia and North America.

\section{MATERIALS AND METHODS}

Analysis of fungal communities in agricultural fields of the RGV. In 2004, communities of Aspergillus section Flavi resident in soils of 14 agricultural fields planted to either maize or cotton were analyzed to determine the relative prevalence of various aflatoxin-producing species. Fields were distributed across $25 \mathrm{~km}^{2}$ and contained within SRS Farms (Mercedes, TX) that provided cropping histories for each field. One to two 150- to 200-g soil samples were taken from each field. Soil samples consisted of 30 to 40 subsamples taken from the top $2 \mathrm{~cm}$ of soil along a $40-$ to $50-\mathrm{m}$ transect $(45,48)$. In 2005, 64 fields with varying histories of sugarcane cropping were sampled throughout the RGV in order to test specific association of A. parasiticus with sugarcane cultivation. Fields were chosen that had never cropped sugarcane, had cropped sugarcane for $<1$ year, had cropped sugarcane for $>1$ year, and those rotated to crops other than sugarcane for 1 year or 3 to 5 years after sugarcane cropping. Continuous sugarcane cropping $(n=21)$ and recent rotation out of sugarcane $(n=6)$ were considered the same treatment because the association between sugarcane and A. parasiticus was first observed in 2004 in a cotton field cropped to sugarcane in 2003. In April, the northern portion (21 fields) of the sugarcane production area was sampled. In June, eight additional fields in the northern portion of the sugarcane-growing region were sampled as well as fields in the eastern $(n=5)$, western $(n=8)$, and southern $(n=17)$ portions of the RGV sugarcane region. In both April and June, fields were selected based on the recorded history of sugarcane cultivation over the previous 10 years. Cropping information was provided by Rio Grande Valley Sugar Growers, Inc. (RGVSG, Santa Rosa, TX).

Soil samples were dried in a forced-air oven (Sheldon Manufacturing, Cornelius, OR) at $45^{\circ} \mathrm{C}$ for $48 \mathrm{~h}$, pulverized by hammering, homogenized by repeated mixing, and transferred to zippered plastic bags. Samples were stored at room temperature until use. Sample suspensions were made by stirring (300 rpm) 10 to $20 \mathrm{~g}$ of homogenized soil in $50 \mathrm{ml}$ of sterilized distilled, deionized water for 10 to 15 min with a magnetic stir bar. Soil suspension (100 to $500 \mu \mathrm{l} / \mathrm{dish}$ ) was spread evenly across the surface of rose Bengal agar modified to favor identification of Aspergillus section Flavi (11) and incubated (darkness, $31^{\circ} \mathrm{C}, 3$ days). After incubation, Aspergillus section Flavi colonies were counted to calculate CFU. Discrete colonies from plates with $\leq 10$ colonies were transferred to $5 \%$ V8 juice medium (13) with sterile wooden sticks. After incubation (darkness, $31^{\circ} \mathrm{C}, 5$ to 7 days), agar plugs of sporulating colonies were transferred to sterile water $\left(2 \mathrm{ml}\right.$ in 5 -ml vial) and stored at $4^{\circ} \mathrm{C}(10)$. All colonies on a plate were counted and at least 15 Aspergillus section Flavi colonies were obtained from each (13).

Plant samples. Sugarcane billets were provided by RGVSG. As components of normal sugar production in RGV, billets (stem pieces) were harvested from $15 \mathrm{RGV}$ locations, prepared for use in commercial plantings, and shipped directly from RGVSG to the School of Plant Sciences, University of Arizona, Tucson. Each billet sample consisted of 10 billets, 40 to $60 \mathrm{~cm}$ in length. Billet samples were surface sterilized by spraying with $80 \%$ ethanol solution and aseptically air dried in a laminar flow hood (NuAire, Plymouth, MN). Additional sugarcane stem samples were collected by hand in Hidalgo (21 fields) and Cameron (6 fields) Counties just prior to harvest in 2005. Mature stalks at least $3 \mathrm{~cm}$ in diameter were selected for sampling; a single piece (30 to $45 \mathrm{~cm}$ long) from each stalk was cut to include the crown at the soil surface. Samples were selected close to the ground because A. parasiticus had been frequently isolated from soils. Billet and hand-collected stem pieces were placed in a forced-air drying oven $45^{\circ} \mathrm{C}$ for 1 to 2 days, minced with a cutting mill (IKA Labortechnik; IKA Werke GmbH \& Co. KG, Staufen, Germany), and stored at room temperature in plastic bags until subjected to dilution plating technique. Homogenized sample $(\approx 5 \mathrm{~g})$ was added to a $7-\mathrm{ml}$ sterile polystyrene tube containing $5 \mathrm{ml}$ of $0.01 \%$ Tween 80 in distilled water. The resulting suspension was mixed for $20 \mathrm{~min}$ by rotation (150 rpm, Roto Shake Genie; Scientific Industries, Bohemia, NY). Aliquots $(100 \mu \mathrm{l})$ of the suspension and a 1:10 dilution in $9 \mathrm{ml}$ of Butterfield's buffer (Hardy Diagnostics, Santa Maria, CA 93455) were subsequently spread aseptically onto three modified rose Bengal agar plates (13). If $>10$ Aspergillus section Flavi cultures were detected on the isolation plates, the quantity of ground sample was decreased to $1 \mathrm{~g}$ and further dilutions were performed, including 1:100 or 1:1,000 serial dilutions of $1-\mathrm{ml}$ sample suspensions.

Data analysis. The study area was $\approx 100 \mathrm{~km}$ wide by $400 \mathrm{~km}$ long, extending from the eastern Texas-Tamaulipas international border in the south to Jackson County in the north. Data were analyzed separately for each county. Quantities of A. parasiticus, A. flavus, and A. tamarii in soil were calculated as the number of

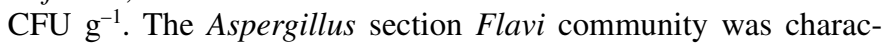
terized for each plant sample as the proportion of the Aspergillus section Flavi community occupied by each species. Community composition was calculated by dividing the number of isolates of each species by the total number of Aspergillus section Flavi isolates and multiplying by 100 . Analysis of variance using general linear models was used to assess effects of county and cropping history on Aspergillus section Flavi community composition and $\mathrm{CFU} \mathrm{g} \mathrm{g}^{-1}$.

Fungal isolates. Thirty-two fungal isolates belonging to Aspergillus section Flavi were used for phenotypic and phylogenetic comparison (Table 1). Isolates were chosen from laboratory and public culture collections to show maximum genetic diversity within the section, and include reference strains and type isolates from A. nomius, A. flavus, and A. parasiticus species (30). In all, 10 putative $A$. parasiticus isolated in association with sugarcane in RGV and 3 from Japan were also included. Cultures were grown in the dark at $31^{\circ} \mathrm{C}$ on $5-2$ medium (10). Isolates were stored on 5-2 (10) 3-mm modified V8 agar plugs in sterile distilled water at $4^{\circ} \mathrm{C}$.

Morphology. After incubation $\left(5-2\right.$ agar, $31^{\circ} \mathrm{C}, 7$ days, darkness) (10), colonies were identified by macroscopic colony and microscopic $(\times 400)$ conidia characteristics $(52,55)$. Isolates with olive-brown to brown near-coffee colonies with thick-walled, distinctly roughened conidia were identified as A. tamarii. A. flavus $\mathrm{L}$ strains were most frequently grayish-green to olive with some colonies moss green in color $(52,53)$. A. parasiticus obtained from RGV were colored deep green, olive green, or olive (52,53). A. flavus and RGV A. parasiticus with similar colony coloring were distinguished by conidial wall ornamentation. Fungi with smooth-surfaced conidia and no ornamentation at $\times 400$ were identified as A. flavus. Fungi with conidial ornamentation ( $\times 400$ magnification) within the range reported for the species $(52,54)$ were identified as $A$. parasiticus. Isolates were also cultured on Aspergillus flavus and parasiticus agar (AFPA) medium $\left(31^{\circ} \mathrm{C}, 5\right.$ days) and development of a bright orange reverse was confirmatory for A. parasiticus or A. flavus $(11,70)$.

Aflatoxin production assay. Aflatoxin production was assayed in a modified Adye and Mateles medium made in $50 \mathrm{mM}$ MES buffer (Research Organics, Cleveland), pH 6.15, containing sucrose and ammonium sulfate as the sole carbon and nitrogen sources, respectively $(13,60)$. Spore suspension was seeded into 250-ml Erlenmeyer flasks containing $70 \mathrm{ml}$ of medium and incubated on an orbital shaker $\left(31^{\circ} \mathrm{C}, 5\right.$ days, darkness, $\left.150 \mathrm{rpm}\right)$. After incubation, the $\mathrm{pH}$ of each culture was measured, and $50 \mathrm{ml}$ 
of acetone was added to each flask to lyse the cells and solubilize the aflatoxin (13). Two 4- $\mu$ l subsamples of acetone/culture suspension were spotted directly onto thin-layer chromatography (TLC) plates (TLC silica gel 60, 20-by-20-cm glass plates; EMD Chemicals, Inc., Gibbstown, NJ) beside aflatoxin standards (Sigma-Aldrich, St. Louis). Plates were developed in 96\% ethyl ether, 3\% methanol, and 1\% distilled deionized water (9); dried, examined under an UV light (365 nM); and scored for presence of $\mathrm{B}$ aflatoxins or $\mathrm{B}$ and $\mathrm{G}$ aflatoxins or aflatoxins below the limit of detection $(1 \mathrm{mg} / \mathrm{kg})$.

Vegetative compatibility analyses. Vegetative compatibility analyses were performed to determine the intimacy of relatedness of $A$. parasiticus isolated from sugarcane and field soils in RGV and Japan. Nitrate-nonutilizing auxotrophs were generated for three A. parasiticus isolates (OPS485, OPS500, and OPS515) (54) from Japanese sugarcane on chlorate medium, as described previously $(12,54)$. Briefly, spore suspensions were seeded into a 3-mm-diameter well in the center of a petri dish containing SEL agar (Czapek-Dox broth with $25 \mathrm{~g}$ of $\mathrm{KClO}_{3}, 50 \mathrm{mg}$ of Rose Bengal, and $20 \mathrm{~g}$ of Bacto agar [Difco Laboratories, Detroit] per liter, $\mathrm{pH}$ 7.0) (12). Auxotrophic sectors formed spontaneously during incubation $\left(31^{\circ} \mathrm{C}, 7\right.$ to 45 days, darkness) were transferred to MIT medium (Czapek-Dox broth with $15 \mathrm{~g}$ of $\mathrm{KClO}_{3}$ and $20 \mathrm{~g}$ Bacto agar [Difco Laboratories] per liter) to stabilize the mutants and eliminate wild-type mycelia (12). Nitrate auxotrophs (nit ${ }^{-}$ mutants) were then phenotyped on media containing $\mathrm{NO}_{3}, \mathrm{NO}_{2}$, or hypoxanthine as sole nitrogen sources, and mutant tester pairs consisting of complimentary $c n x^{-}$and niaD mutants were developed for each isolate (3). The nit mutants from sugarcaneassociated $A$. parasiticus isolates from $\mathrm{RGV}$ were paired on starch medium $\left(3.0 \mathrm{~g}\right.$ of $\mathrm{NaNO}_{3}, 1.0 \mathrm{~g}$ of $\mathrm{K}_{2} \mathrm{HPO}_{4}, 0.5 \mathrm{~g}$ of $\mathrm{MgSO}_{4}, 0.5 \mathrm{~g}$ of $\mathrm{KCl}, 36 \mathrm{~g}$ of dextrose, and $1.0 \mathrm{ml}$ of $\mathrm{A} \& \mathrm{M}$ micronutrients per liter) (18) with the tester pairs for each Japanese isolate to assess potential membership (4). Plates were incubated $\left(31^{\circ} \mathrm{C}, 10\right.$ days, darkness) and VCG membership was indicated by auxotroph complementation resulting in wild-type growth in the zone of mycelial interaction between at least one tester and the isolate nit mutant. The tester pair for the most common VCG, OPS500, was deposited at the Fungal Genetics Stock Center (accession numbers FGSC A1915 and A1916).

DNA isolation and polymerase chain reaction amplification. For the following procedures, isolates previously transferred by single spore were cultured on $5-2$ agar $\left(31^{\circ} \mathrm{C}, 5\right.$ days, darkness) (10). After incubation, spores were collected with a sterile cotton swab and suspended in sterile distilled water. The resultant spore suspension $(100 \mu \mathrm{l})$ was added to $70 \mathrm{ml}$ of sterile potato dextrose broth (Difco Laboratories) in a 250-ml Erlenmeyer flask and incubated on a rotary shaker $\left(5\right.$ days, $31^{\circ} \mathrm{C}$, darkness, $150 \mathrm{rpm}$ ). Mycelia were captured on Miracloth (EMD Millipore, Billerica, MA) and DNA was isolated using the FastDNA SPIN Kit and the Fast Prep Instrument (Qbiogene, Inc. Carlsbad, CA). DNA was stored in buffer at either -20 or $-80^{\circ} \mathrm{C}$ (long-term). Three genes (ITS1, aflR, and niaD) were directly sequenced. Polymerase chain reaction (PCR) of internal transcribed spacer (ITS) 1 used the primers ITS4 and ITS5 (435 bp), as previously described (92). A portion of the gene encoding the aflatoxin transcription factor aflR $(1.6 \mathrm{~kb})$ was amplified in three pieces using primers AFLR-F (5'-GGAAACAAGTCTTTTCTGG-3') and AFLR-R (5'-CAGA GCGTGTGGTGGTTGAT-3'), AFLR1F (5'-AGAGAGCCAACT GTCGGACCAA-3') and AFLR1R (5'-GGGTGACCAGAGAAC TGCGTGAT-3'), and AFLR2F (5'-GACTTCCGGCGCATAACA CGTA-3') and AFLR2R (5'-ACGGTGGCGGGACTGTTGCTA CA-3') (27). aflR primers did not work well for three Asian $A$. parasiticus isolates. For these isolates, the entire aflR region was amplified using primers AFLJR1F (5'-CAT GGC TGA GGA TAG CTC GTG-3') and AFLJR20R (5'-GTG TGT TGA TCG ATC GGC CAG-3') (27). The resulting amplicons were then successfully used as the template for the three initial aflR primer pairs. A portion of the nitrate reductase gene $(2.2 \mathrm{~kb})$, niaD, was amplified in three pieces using the primers NIADF (5'-CGGACGATAA

TABLE 1. Aspergillus section Flavi isolates used in this study

\begin{tabular}{|c|c|c|c|c|c|c|}
\hline Isolate & Other names & Species & Location $^{z}$ & Substrate & Citation & Aflatoxins \\
\hline NRRL 13137 & M93, ATCC 15546 & nomius & Illinois & Wheat & 55 & $\mathrm{BG}$ \\
\hline AF36 & YV36 & flavus & Arizona & Cottonseed & 10 & None \\
\hline $\mathrm{V}$ & MR17 & flavus & Arizona & Cottonseed & 10 & $\mathrm{~B}$ \\
\hline AF13 & ATCC 96044 & flavus & Arizona & Citrus soil & 10 & B \\
\hline P19 & YV19 & flavus & Arizona & Bermuda grass soil & 10 & $\mathrm{~B}$ \\
\hline $\mathrm{AF} 12$ & ATCC MYA-382 & flavus & Arizona & Cotton field soil & 10 & B \\
\hline AF42 & ATCC MYA-383 & flavus & Arizona & Cottonseed & 10 & $\mathrm{~B}$ \\
\hline AF70 & ATCC MYA-384 & flavus & Arizona & Cotton field soil & 10 & B \\
\hline OPS417 & $\ldots$ & parasiticus & Vietnam & Peanut & 54 & $\mathrm{BG}$ \\
\hline NRRL 2999 & ATCC 26691 & parasiticus & Uganda & Peanut & 75 & $\mathrm{BG}$ \\
\hline OPS393 & $\ldots$ & parasiticus & Vietnam & Peanut & 54 & BG \\
\hline BN009E & $\ldots$ & parasiticus & Benin & Mixed crop soil & 70 & $\mathrm{BG}$ \\
\hline CP461 & ATCC-62882 & parasiticus & Georgia & Peanut & 22 & None \\
\hline NRRL 424 & $\ldots$ & parasiticus & Georgia & Peanut field soil & 68 & $\mathrm{BG}$ \\
\hline OPS651 & $\ldots$ & parasiticus & China & Peanut & 54 & $\mathrm{BG}$ \\
\hline NRRL 4123 & $\ldots$ & parasiticus & Georgia & Maize & 68 & $\mathrm{BG}$ \\
\hline SU1 & ATCC 56775 & parasiticus & Uganda & Peanut & 56 & $\mathrm{BG}$ \\
\hline NRRL 465 & CBS 571.65 & parasiticus & Unknown & Unknown & 91 & BG \\
\hline NRRL 502 & $\ldots$ & parasiticus & Hawaii & Mealybug & 68 & BG \\
\hline A17-H & $\ldots$ & parasiticus & RGV & Sugarcane field soil & Current study & $\mathrm{BG}$ \\
\hline A17-N & FGSC A1921 & parasiticus & RGV & Sugarcane field soil & Current study & $\mathrm{BG}$ \\
\hline Gal5-N & $\ldots$ & parasiticus & RGV & Sugarcane field soil & Current study & $\mathrm{BG}$ \\
\hline Gal22-J & FGSC A1917 & parasiticus & RGV & Sugarcane field soil & Current study & $\mathrm{BG}$ \\
\hline Har1-AC & $\ldots$ & parasiticus & RGV & Cotton lint & Current study & $\mathrm{BG}$ \\
\hline Har7-O & FGSC A1918 & parasiticus & RGV & Cotton lint & Current study & $\mathrm{BG}$ \\
\hline Mad1-B & $\ldots$ & parasiticus & RGV & Sugarcane field soil & Current study & $\mathrm{BG}$ \\
\hline $\mathrm{Mad} 2-\mathrm{H}$ & FGSC A1919 & parasiticus & RGV & Sugarcane field soil & Current study & $\mathrm{BG}$ \\
\hline OPS485 & $\ldots$ & parasiticus & Japan & Sugarcane field soil & 54 & $\mathrm{BG}$ \\
\hline OPS500 & $\ldots$ & parasiticus & Japan & Sugarcane field soil & 54 & $\mathrm{BG}$ \\
\hline OPS515 & $\ldots$ & parasiticus & Japan & Sugarcane field soil & 54 & BG \\
\hline Ray2-F & $\ldots$ & parasiticus & RGV & Sugarcane field soil & Current study & $\mathrm{BG}$ \\
\hline Ray4-C & $\ldots$ & parasiticus & $\mathrm{RGV}$ & Sugarcane field soil & Current study & BG \\
\hline
\end{tabular}

${ }^{\mathrm{z}} \mathrm{RGV}=$ Rio Grande Valley of Texas. 
GCAACAACAC-3') and NIADR (5'-GAGCCGTTACATTCT CACAC-3'), NIADBF (5'-ACGGCCGACAGAAGTGCTGA-3') and NIADBR (5'-ACGGGGAGTCTCTTCGCCCA-3'), and NIAD3F (5'-GTCACTACGGCACATCTA-3') and NIAD3R (5'ATGCCTACAGGATGGATG-3'). PCR reactions were carried out in $20 \mu \mathrm{l}$ of AccuPower HotStart PCR PreMix polypropropylene tube strips (Bioneer Corporation, Daejeon, Korea) using $18 \mu \mathrm{l}$ of autoclaved, distilled, deionized water and $1 \mu \mathrm{l}$ of genomic DNA (15 ng/ $\mu$ l final DNA concentration). PCR conditions for ITS primers included a denaturation and hot start step of $5 \mathrm{~min}$ at $94^{\circ} \mathrm{C}$; followed by 35 cycles of $94^{\circ} \mathrm{C}$ for $20 \mathrm{~s}, 54.3^{\circ} \mathrm{C}$ for $20 \mathrm{~s}$, and $72^{\circ} \mathrm{C}$ for $30 \mathrm{~s}$; and final extension at $72^{\circ} \mathrm{C}$ for $10 \mathrm{~m}$. PCR conditions for $a f l R$ primers were similar, except the extension was $90 \mathrm{~s}$ and annealing was at $47^{\circ} \mathrm{C}$ for AFLR F-R, $59^{\circ} \mathrm{C}$ for AFLR $1 \mathrm{~F}-1 \mathrm{R}, 57^{\circ} \mathrm{C}$ for AFLR $2 \mathrm{~F}-2 \mathrm{R}$, and $55^{\circ} \mathrm{C}$ annealing and 2.5 -min extension for AFLJR 1F-20R. PCR conditions for the NiaD region were similar, except annealing temperatures were $52^{\circ} \mathrm{C}$ for primers NIAD F-R and NIAD $3 \mathrm{~F}-3 \mathrm{R}$ and $57^{\circ} \mathrm{C}$ for primers NIAD BF-BR. Amplicons were separated by electrophoresis on $1 \%$ agarose gels and evaluated for size and singularity. Excess primers and unincorporated nucleotides were degraded with ExoSAP-IT (USB Corporation, Cleveland) $(1 \mu \mathrm{l}$ of ExoSAP-IT in $16 \mu \mathrm{l}$ of PCR product at $37^{\circ} \mathrm{C}$ for $1 \mathrm{~h}$, followed by $85^{\circ} \mathrm{C}$ for $15 \mathrm{~min}$ ). Purified PCR products were sequenced twice (once in each direction) by the University of Arizona sequencing facility, UAGC, with a 3730XL DNA Analyzer (Applied Biosystems, Foster City, CA). Novel A. parasiticus sequences were submitted to the National Center for Biotechnology Information GenBank with accession numbers KC769488-KC769508 for aflR and KC782772-KC782791 for niaD.

Phylogenetic analyses. Sequences were edited and aligned using Geneious Pro (version 4.8.2; Biomatters Ltd., Auckland, New Zealand). The three sugarcane-associated $A$. parasiticus isolates from Japan as well as two isolates from each of six RGV sampling sites were included in the phylogenetic analyses. Although, A. parasiticus isolates directly isolated from sugarcane plant samples were not included in the phylogenies, several Texas isolates were included that were known to belong to VCGs isolated repeatedly from sugarcane tissues. Two A. parasiticus isolates from cotton lint collected from RGV fields previously cropped to sugarcane were also included. JModelTest 0.1 was used to identify the model of nucleotide substitution that best fit the data from each locus (71). Phylogenetic trees were constructed with both maximum-likelihood (ML) (Phylip version 3.68) (29), and maximum-parsimony (MP) (Paup 4.0b10) (81) methods. MP analyses utilized heuristic searches with random stepwise addition, tree bisection-reconnection branch swapping, and 100 replicates. Gaps were treated as missing data. Branch supports for all analyses were estimated using 1,000 bootstrap replicates, with a heuristic search consisting of 100 randomaddition replicates for each bootstrap replicate. All characteristics were unordered and equally weighted.

\section{RESULTS}

Association of $\boldsymbol{A}$. parasiticus with sugarcane. Among 158 agricultural fields sampled in an area extending from the Upper Coast through RGV in 2004 and 2005, A. parasiticus was only recovered from soils in sugarcane-producing RGV counties and was never isolated outside sugarcane-producing counties (limit of detection $=7 \%$ within fields and $0.1 \%$ across non-sugarcane fields) (Table 2). Within three sugarcane-producing counties, proportions of Aspergillus section Flavi communities comprising A. parasiticus in fields were 0 to $100 \%$. Abundance of Aspergillus section Flavi fungi in soil $\left(\mathrm{CFU} \mathrm{\textrm {g } ^ { - 1 }}\right)$ differed with sugarcane cropping history $\left(t_{1,56}=5.50, P<0.0001\right)$ and varied among counties regardless of sugarcane cropping $\left(F_{5,152}=26.70, P<\right.$ $0.0001)$. Sugarcane-cropping counties yielded the fewest section Flavi fungi, with fungi in fields at 2.66 to $323.8 \mathrm{CFU} \mathrm{g}^{-1}$ (Table 2). Counties that did not crop sugarcane yielded Aspergillus section Flavi fungi at 10.7 to $4,400.7 \mathrm{CFU} \mathrm{g}^{-1}$.

The association of $A$. parasiticus with sugarcane cultivation was consistent over the 2 years studied in RGV (Table 3). In Hidalgo County in 2004 and on two dates in 2005, A. parasiticus was found only in the 21 fields cropped to sugarcane in the previous 5 years (Table 3). No A. parasiticus was detected in the 42 fields not cropped to sugarcane in the previous 5 years. $A$. parasiticus was detected only in one field in Cameron County 2005 sampling without a history of sugarcane $(4.8 \%$ A. parasiticus) (Table 3). Differences in frequencies of $A$. parasiticus between sugarcane and non-sugarcane fields were consistent in both April and June within sugarcane-producing counties (Table 3). A. flavus CFU/g of soil was similar in both counties and both sugarcane and non-sugarcane fields (Table 3).

The proportion of the Aspergillus section Flavi community comprising A. parasiticus was dependent upon cropping history, with both the duration of sugarcane cropping and the number of years out of sugarcane significantly influencing the percent $A$. parasiticus $\left(F_{3,74}=51.23, P<0.0001\right)$ (Fig. 1). Percent $A$. parasiticus was greatest in the 27 fields either $<2$ years out of sugarcane or with one or more sugarcane harvests. Analysis of similarity testing revealed that the Aspergillus section Flavi communities of fields in continuous sugarcane cropping and those rotated to other crops for $<2$ years were not statistically different $(R=-0.1822, P=0.97)$; therefore, these two potential treatments were pooled in the analyses. Ten fields planted to sugarcane but

TABLE 2. Aspergillus section Flavi communities in Texas counties that do or do not crop sugarcane

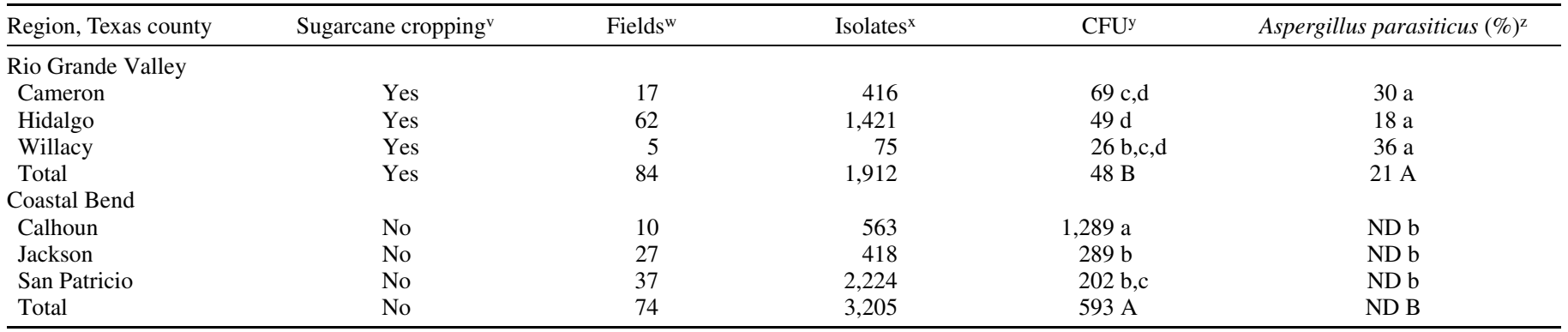

${ }^{v}$ Yes indicates sugarcane was commercially cropped in the county within the past 25 years.

${ }^{\text {w }}$ Composite soil samples ( $\approx 200 \mathrm{~g}$ ) composed of 30 to 40 subsamples along an 80 - to 100-m diagonal were taken from each field (1 to 6 samples/field). In counties with sugarcane cropping, both fields that had been recently cropped to sugarcane and fields without sugarcane for the past 5 years.

x Only Aspergillus section Flavi fungi were enumerated and isolated (at least 12 isolates from each soil sample).

${ }^{y}$ CFU were calculated per gram of soil. CFU with a common letter (lowercase) are not significantly different $(P<0.05)$ by Fisher's protected least significant difference (LSD) test; totals not followed by the same letter (A or B) are significantly different by Student's $t$ test (two sided; $P<0.0001$ ).

${ }^{\mathrm{z}} \mathrm{ND}=$ A. parasiticus not detected (limit of detection $=7 \%$ ). Percent $A$. parasiticus was significantly different among treatments $\left(F_{5,152}=6.08, P<0.0001\right)$. Percentages not followed by the same letter (a, b, A, or B) are significantly different using Fisher's protected LSD test. 
sampled prior to the first harvest had a similar percent $A$. parasiticus as six fields rotated to non-sugarcane crops for 3 to 5 years. A. parasiticus communities in fields 3 to 5 years out of sugarcane also were not statistically different from fields never cropped to sugarcane. Cropping history also influenced the proportion of the Aspergillus section Flavi community comprising $A$. flavus $\left(F_{3,74}=54.78, P<0.0001\right)$, with $A$. flavus dominating fields without recent sugarcane cropping (Fig. 1).

Overall, A. parasiticus was the member of Aspergillus section Flavi most frequently associated with both sugarcane billets obtained from the RGVSG sugar mill and plant stems harvested by hand (Table 3 ). A. parasiticus was present in every plant sample taken but A. flavus was not detected in 13 of 77 plant samples. One A. tamarii isolate $(<0.01 \%$ of the total Aspergillus section Flavi community) was recovered from a field-collected sugarcane sample. Billet samples from three counties had similar Aspergillus section Flavi communities, with A. parasiticus percentages higher than A. flavus percentages (Table 4). Handharvested stems had a greater percentage of A. flavus than commercial billet samples (Table 4). The community in handcollected stems differed by county, with A. flavus dominating in Cameron County and A. parasiticus dominating samples from Hidalgo (Table 4). Hand-collected plant samples and billets were not symptomatic of any disease and were not infested by pink sugarcane mealybugs.

Sugarcane-associated A. parasiticus isolates from Japan and the United States are distinct from other $A$. parasiticus isolates. Based both on morphology and DNA sequence data, $A$. parasiticus from Texas sugarcane fields was more similar to A. parasiticus from Japanese sugarcane fields than to either A. flavus or A. parasiticus not associated with sugarcane. The three $A$. parasiticus isolates from Japanese sugarcane were morphologically indistinguishable from RGV A. parasiticus. Colony color and spore ornamentation were similar to that for non-sugarcane-associated $A$. parasiticus but non-sugarcane-associated $A$. parasiticus produced sclerotia on Czapek's medium whereas sugarcane-associated A. parasiticus did not, although sclerotia production is an unreliable taxonomic characteristic (30). All RGV A. parasiticus isolates assayed produced aflatoxins B and G. In all, 24\% of the 312 Texas A. parasiticus, 248 from soils and 64 from plant samples, were vegetatively compatible with one of the three Japanese sugarcaneassociated $A$. parasiticus isolates. Fifteen isolates from sugarcane tissues were compatible with one of the sugarcane-associated $A$. parasiticus isolates. The VCG to which OPS500 belongs was the most common (47 RGV isolates), followed by the VCGs of OPS485 (22 RGV isolates) and OPS515 (3 RGV isolates).

Sequence of ITS regions (539 bp) contained only four parsimony-informative characteristics among 39 A. flavus and
A. parasiticus isolates. ML phylogenies from ITS sequence data showed three clades with $>90 \%$ bootstrap support. All A. flavus isolates were restricted to a single clade, sister to the two clades that contained all the A. parasiticus isolates. A. parasiticus collected in association with sugarcane occupied a single clade, sister to A. parasiticus from culture collections, although sugarcane-associated $A$. parasiticus was only separated from culture collection A. parasiticus by one step and from A. flavus by four steps (data not shown).

Similar topologies were observed in the $\operatorname{aflR}(1.5 \mathrm{~kb})$ and niaD $(2.2 \mathrm{~kb})$ trees generated from sequences that provided 66 and 153 parsimony-informative characteristics, respectively. The single most parsimonious MP phylogeny generated from the aflR sequence (Fig. 2) contained a bifurcated A. parasiticus clade $(84 \%$

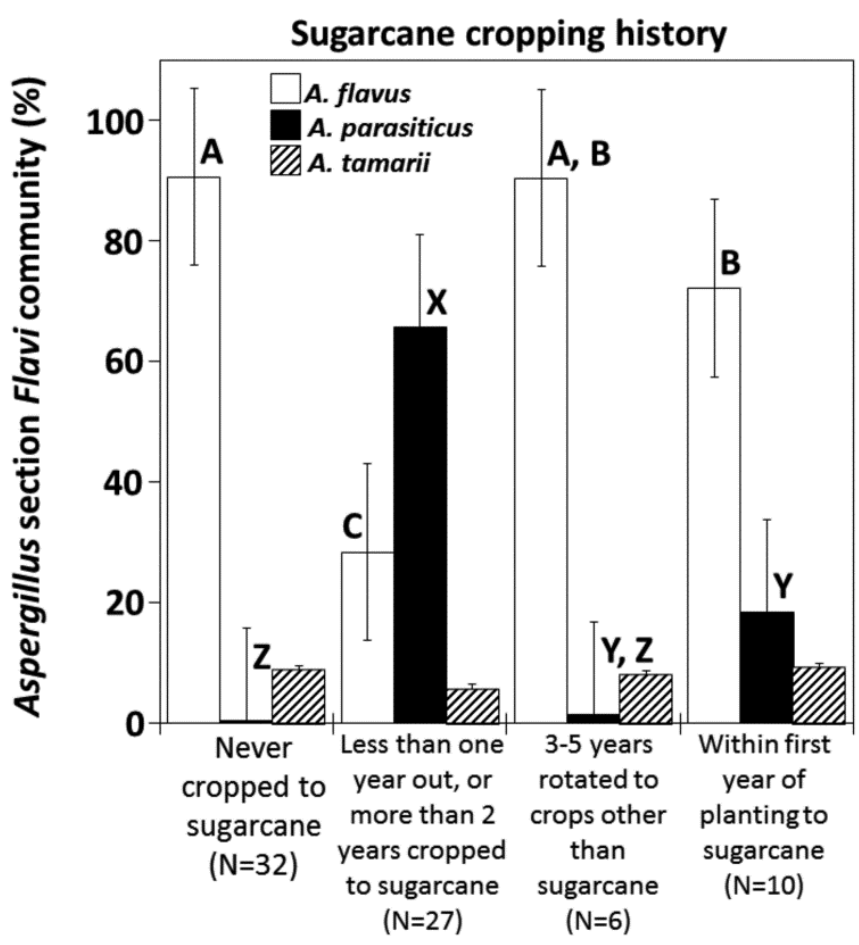

Fig. 1. Percentage of Aspergillus section Flavi communities composed of Aspergillus flavus, A. tamarii, and A. parasiticus in Rio Grande Valley field soils with known sugarcane cropping histories. An average of 16 section Flavi isolates were collected from each soil. Levels of A. flavus (A, B, and C) and A. parasiticus (X, Y, and Z) without a common letter are significantly different by Fisher's protected least significant difference test $(P<0.05)$. Levels of $A$. tamarii were statistically similar for all treatments.

TABLE 3. Aspergillus section Flavi community from fields cropping and not cropping sugarcane in the Rio Grande Valley, Texas

\begin{tabular}{|c|c|c|c|c|c|c|}
\hline \multirow[b]{2}{*}{ Texas county } & \multirow[b]{2}{*}{ Sample date } & \multirow[b]{2}{*}{ Crop history ${ }^{\mathrm{x}}$} & \multirow[b]{2}{*}{ Fields $(N)^{\mathrm{y}}$} & \multicolumn{3}{|c|}{ Species composition $(\mathrm{CFU})^{\mathrm{z}}$} \\
\hline & & & & Aspergillus flavus & A. parasiticus & A. tamarii \\
\hline \multirow[t]{6}{*}{ Hidalgo } & April 2004 & Sugarcane & 2 & $4 \mathrm{~b}$ & $9 \mathrm{a}$ & $\mathrm{ND}$ a \\
\hline & & No sugarcane & 23 & $48 \mathrm{a}$ & $\mathrm{ND} b$ & $2 \mathrm{a}$ \\
\hline & April 2005 & Sugarcane & 4 & $4 \mathrm{~b}$ & $15 \mathrm{a}$ & $1 \mathrm{a}$ \\
\hline & & No sugarcane & 17 & $61 \mathrm{a}$ & $\mathrm{ND} b$ & $2 \mathrm{a}$ \\
\hline & June 2005 & Sugarcane & 14 & $30 \mathrm{a}$ & $9 \mathrm{a}$ & $1 \mathrm{a}$ \\
\hline & & No sugarcane & 2 & $51 \mathrm{a}$ & $\mathrm{ND} b$ & $4 \mathrm{a}$ \\
\hline \multirow[t]{4}{*}{ Cameron } & June 2005 & Sugarcane & 11 & $36 \mathrm{a}$ & $26 \mathrm{a}$ & $5 \mathrm{a}$ \\
\hline & & No sugarcane & 6 & $69 \mathrm{a}$ & $0.8 \mathrm{~b}$ & $2 \mathrm{a}$ \\
\hline & & Sugarcane total & 31 & $27 \mathrm{~B}$ & $16 \mathrm{~A}$ & $3 \mathrm{~A}$ \\
\hline & & No sugarcane total & 48 & $55 \mathrm{~A}$ & $0.1 \mathrm{~B}$ & $2 \mathrm{~A}$ \\
\hline
\end{tabular}

x Sugarcane $=$ field cropped to sugarcane at least once within the previous 5 years and No sugarcane $=$ field not cropped to sugarcane during the previous 5 years.

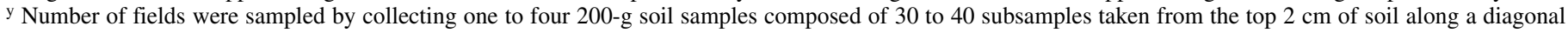
transect of 80 to $100 \mathrm{~m}$.

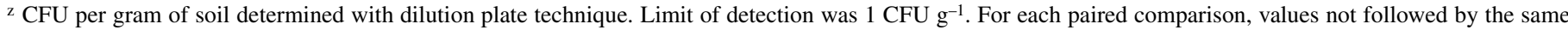
letter in each column are significantly different with a two-sided Student's $t$ test $(P<0.05)$. Statistical testing was performed on log +1 transformations of the CFU data. ND = not detected. 
bootstrap support), sister to A. flavus. The A. parasiticus clade showed two highly supported lineages: one including only sugarcane-associated isolates and the other including only isolates collected from non-sugarcane sources, which included the mealybug-isolated lectotype. These lineages were also distinct and well supported in ML analyses, with 98 and $99 \%$ bootstrap support for the non-sugarcane- and sugarcane-associated clades, respectively. The MP phylogeny created from the niaD sequence (Fig. 3) maintained the separation between the clade containing A. flavus (100\% bootstrap support) and that containing A. parasiticus $(98 \%$ bootstrap support). All isolates associated with sugarcane again formed a strongly supported clade ( $97 \%$ bootstrap support); however, this clade groups within a polytomy containing the $A$. parasiticus isolates from crops other than sugarcane. ML phylogenies also separated $A$. parasiticus and A. flavus species into highly supported clades ( $>90 \%$ bootstrap support), and bifurcated $A$. parasiticus into sister clades separating isolates from sugarcane and those from other sources ( $>88 \%$ bootstrap support; data not shown).

\section{DISCUSSION}

This is the first report to show that sugarcane specifically influences presence and persistence of one lineage of aflatoxinproducing fungi in RGV. A. parasiticus is almost exclusively associated with sugarcane in RGV, occurring primarily on sugarcane stems and in field soils with a recent history of sugarcane cropping. A. parasiticus from $\mathrm{RGV}$ sugarcane form a distinct phylogenetic lineage with Japanese isolates to the exclusion of $A$. parasiticus from other crops. The evolutionary divergence of $A$. parasiticus found in association with sugarcane from the rest of the species, even the ex-type isolate (NRRL 502) from a sugarcane mealybug (77), suggests that the association between $A$. parasiticus and sugarcane is not ephemeral. Vegetative compatibility analyses indicate that $A$. parasiticus VCGs associated with sugarcane in Japan are common among the RGV A. parasiticus isolates from both sugarcane tissues and soils planted to sugarcane. Although the physiological basis for the observed sugarcane-A. parasiticus relationship is unknown, A. parasiticus dominates the Aspergillus section Flavi community resident on RGV sugarcane and, in so doing, influences the aflatoxin-producing potential of that community and the etiology of aflatoxin contamination of both sugarcane products and rotation crops $(49,74)$. Thus, associations of $A$. parasiticus with specific hosts impact the epidemiology of aflatoxin contamination by influencing the average aflatoxin-producing potential of fungal communities. Increased aflatoxin-producing potential has been associated with the most lethal aflatoxin contamination events globally
$(73,74)$, and atoxigenic $A$. parasiticus are rare $(22,76,88)$. Aflatoxin-producing fungi are saprophytes and facultative pathogens with broad host ranges, including plants and animals $(16,36,78)$. Individual isolates infect and decay hosts that diverged millions of years before the present (35). However, a broad potential host range does not eliminate the possibility of host preference or competitive advantage among aflatoxin-producing fungi (63).

Sugarcane cultivation is frequently accompanied by specific lineages of $A$. parasiticus which require host cultivation for persistence. A. parasiticus was dominant in RGV fields rotated out of sugarcane for 1 year but undetectable in soil Aspergillus section Flavi communities after 5 years (Fig. 1; Table 4). A. parasiticus has most frequently been associated with peanut in the United States $(39,41)$, and previous reports correlate the presence of $A$. parasiticus with soils suitable for peanut cultivation. However, peanut production has not been shown to increase proportions of A. parasiticus within soil fungal communities and rotation out of peanut has not been associated with loss of $A$. parasiticus (41). A. parasiticus is found in the peanut-growing regions of the southern United States but, elsewhere, peanut crops are not always associated with $A$. parasiticus $(50,59,76,86)$ and, in some regions, $A$. flavus and not $A$. parasiticus is the primary causal agent of aflatoxin contamination of peanut $(26,58,85)$. A parasiticus isolates found in RGV were more closely related to $A$. parasiticus associated with sugarcane production in Japan than to U.S. isolates not associated with sugarcane. Spore banks have been implicated as the source of primary inoculum for $A$. parasiticus isolates infecting crops $(30,32,38,44,76)$. A parasiticus has been described as the member of Aspergillus section Flavi best adapted to the soil habitat (39-41). Sugarcane-associated A. parasiticus isolates are divergent from the rest of the species and, based on the response of these aflatoxin-producers to sugarcane production, occupy a distinct ecological niche. The A. parasiticus lectotype (NRRL502) is more closely related to those A. parasiticus isolates from maize and peanut than A. parasiticus found in association with sugarcane in RGV, although the lectotype was isolated from a sugarcane mealybug. Although peanut-associated A. parasiticus does not appear to be as host-dependent as sugarcane-associated $A$. parasiticus, host associations may drive species and population level divergence $(19,64,79)$.

A. parasiticus isolates found on sugarcane in $\mathrm{RGV}$ were as phylogenetically distinct from $A$. parasiticus isolated from other crops as both groups are from $A$. flavus. In phylogenies based on aflR sequence, sugarcane-associated $A$. parasiticus form a sister clade to other $A$. parasiticus isolates, while niaD phylogenies nest sugarcane-associated $A$. parasiticus in a clade shared with $A$. parasiticus from other sources. Morphological resemblance of the

TABLE 4. Composition of Aspergillus section Flavi community isolated from sugarcane billets and field-collected stem pieces in RGV 2005

\begin{tabular}{|c|c|c|c|c|c|c|c|c|}
\hline \multirow[b]{2}{*}{ Source, county ${ }^{\mathrm{w}}$} & \multirow[b]{2}{*}{$N^{\mathrm{x}}$} & \multicolumn{2}{|c|}{ Aspergillus parasiticus ${ }^{\mathrm{y}}$} & \multicolumn{2}{|c|}{ A. flavus $^{\mathrm{y}}$} & \multirow[b]{2}{*}{ Total isolates ${ }^{\mathrm{y}}$} & \multirow[b]{2}{*}{ A. parasiticus $(\%)^{\mathrm{z}}$} & \multirow[b]{2}{*}{ A. flavus $(\%)^{\mathrm{z}}$} \\
\hline & & With & Without & With & Without & & & \\
\hline \multicolumn{9}{|l|}{ Billet } \\
\hline Cameron & 19 & 19 & 0 & 1 & 18 & 175 & $99(\mathrm{~A})$ & $1(\mathrm{C})$ \\
\hline Hidalgo & 10 & 10 & 0 & 3 & 7 & 148 & 89 (A) & $11(\mathrm{~B}, \mathrm{C})$ \\
\hline Willacy & 1 & 1 & 0 & 0 & 1 & 13 & 100 (A) & $\mathrm{ND}(\mathrm{A}, \mathrm{B}, \mathrm{C})$ \\
\hline Total & 30 & $30 \mathrm{~A}$ & $0 \mathrm{~B}$ & $4 \mathrm{~B}$ & $26 \mathrm{~A}$ & 336 & $95(\mathrm{~A})$ & $5(\mathrm{~B})$ \\
\hline \multicolumn{9}{|l|}{ Field } \\
\hline Cameron & 24 & 11 & 13 & 20 & 4 & 108 & 29 (B) & $71(\mathrm{~A})$ \\
\hline Hidalgo & 23 & 19 & 4 & 14 & 9 & 233 & $74(\mathrm{~A})$ & $25(\mathrm{~B})$ \\
\hline Total & 47 & $30 \mathrm{~B}$ & $17 \mathrm{~A}$ & $34 \mathrm{~A}$ & $13 \mathrm{~B}$ & 341 & 52 (B) & 48 (A) \\
\hline
\end{tabular}

${ }^{\mathrm{w}}$ Conventionally harvested billet samples provided by Rio Grande Valley Sugar Growers, Inc., sugar mill; field samples were hand-collected in June.

${ }^{x}$ Number of individual plants sampled; 1 stem per sample.

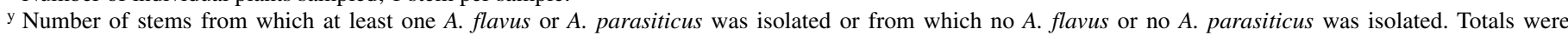
subjected to statistical analyses. Comparisons frequencies of $A$. parasiticus and $A$. flavus were compared between the total field and billet samples. Numbers not followed by the same letter differ by the Pearson's $\chi^{2}$ test; $\chi_{1,77}^{2}=13.9, P=0.0002$, for number of $A$. parasiticus-positive stems and $\chi^{2}{ }_{1,77}=25.5, P<0.0001$, for number of $A$. flavus-positive stems.

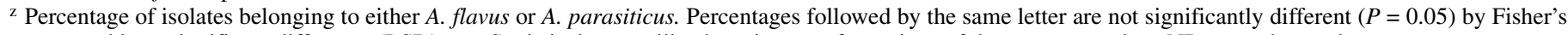
protected least significant difference $($ LSD) test. Statistical tests utilized arcsine transformations of the percentage data. ND $=$ not detected. 
genetics of $A$. parasiticus associated with sugarcane to those associated with other crops (Figs. 2 and 3) invalidates the use of conidial shape and colony color for identification of divergent adaptations and distributions among lineages within Aspergillus section Flavi. However, morphology of sclerotia and habits of sclerotia formation may provide useful characteristics for differentiating A. parasiticus clades, as is the case for other species within Aspergillus section Flavi $(10,28,30)$. Molecular markers specific to each lineage would facilitate investigations on lineage specific characteristics, and the sequence data developed for niaD and aflR during the current study may be an adequate basis for such markers, whereas ITS sequence was uninformative.

A. parasiticus was previously associated with aflatoxins in raw sugar but frequencies and severities of contamination in sugar products are unreported (84) because procedures for refining sugar from sugarcane do not concentrate aflatoxins in either sugar or valuable byproducts. Concentration of aflatoxins does occur during production of both high-protein meals in vegetable oil

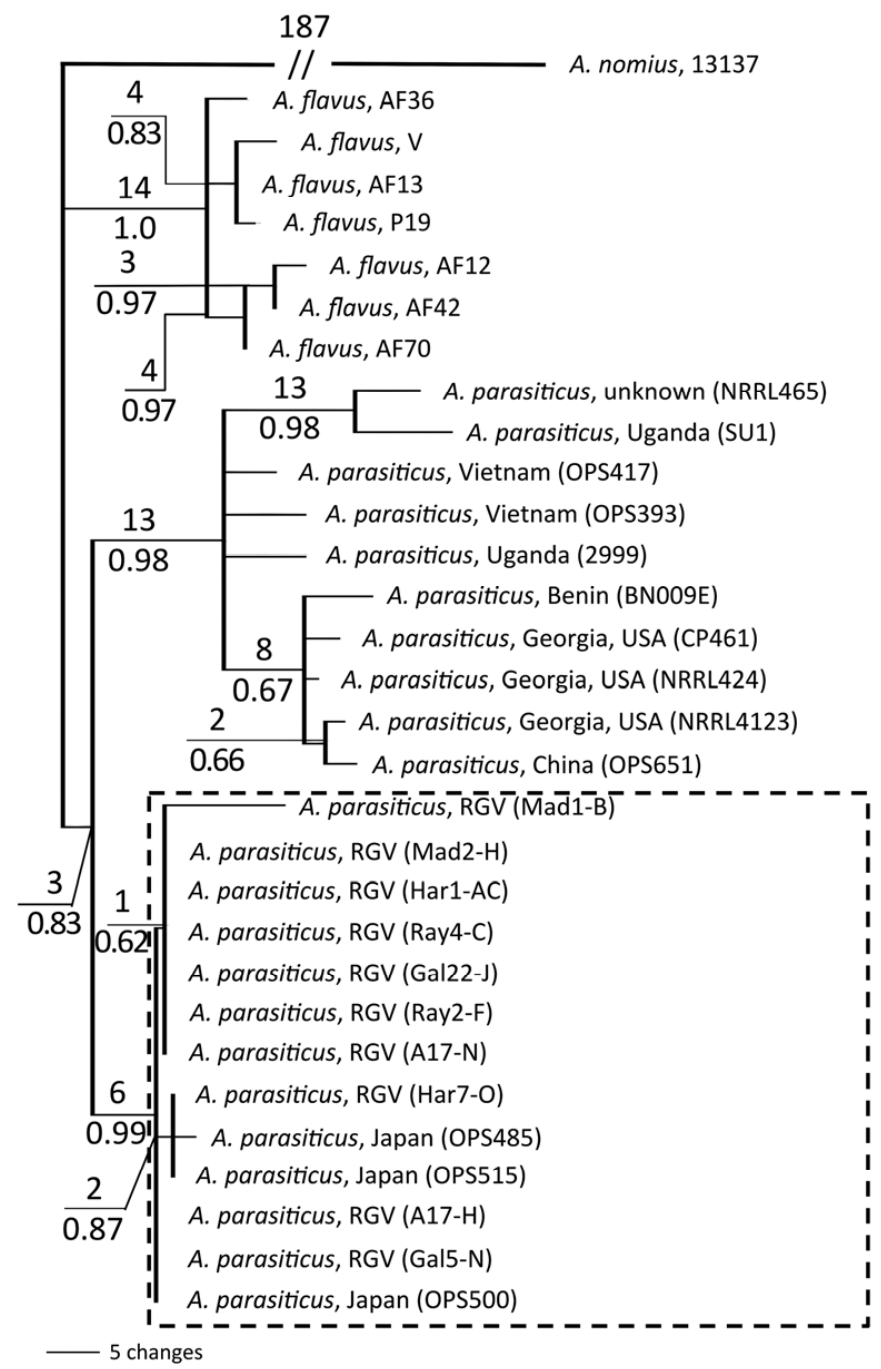

Fig. 2. Aspergillus section Flavi phylogeny inferred by maximum parsimony from $1.5 \mathrm{~kb}$ of aflR, the gene encoding the transcription factor that regulates many aflatoxin biosynthesis genes. The single most parsimonious tree is shown, with nodes of $<80 \%$ bootstrap support collapsed. Maximum-likelihood analysis resulted in similar topology, with $>90 \%$ bootstrap support for the clades separating Aspergillus flavus, sugarcane-associated A. parasiticus, and A. parasiticus from other sources. Numbers above branches are branch lengths proportional to the number of character changes and those below are bootstrap frequencies based on 1,000 replicates. Labels on the phylogeny are either culture collection names or laboratory working names. The tree is rooted with A. nomius (NRRL 13137) as the outgroup. All A. parasiticus isolates associated with sugarcane cropping are included in the dashed box. production and dry distiller grains in ethanol production $(14,95)$. Indeed, high heat and calcium hydroxide clarification during table-sugar processing may degrade any aflatoxins present $(6,21)$ but raw sugar products made without harsh treatments may be at higher risk of aflatoxin contamination $(54,82)$. Despite the limited risk posed to sugar products, A. parasiticus causes severe contamination of staple crops, including peanut, produced in Africa and North America $(16,20,39)$. The impact of sugarcane-associated $A$. parasiticus on aflatoxin contamination in other crops in the United States is unknown. Commercial crops in the RGV are frequently assayed for total aflatoxin content, and $\mathrm{G}$ aflatoxins, a metabolite of $A$. parasiticus but not A. flavus, are not quantified independently. However, two A. parasiticus isolates from cotton lint in the RVG were found to be of the type associated with sugarcane in the current study. High levels of persistence of sugarcane-associated $A$. parasiticus in field soils 1 year after rotation out of sugarcane provides potential for rotation crop exposure to these aflatoxin-producers.

A. parasiticus isolates dominated the Aspergillus section Flavi community in stem pieces (billets) prepared for planting and were

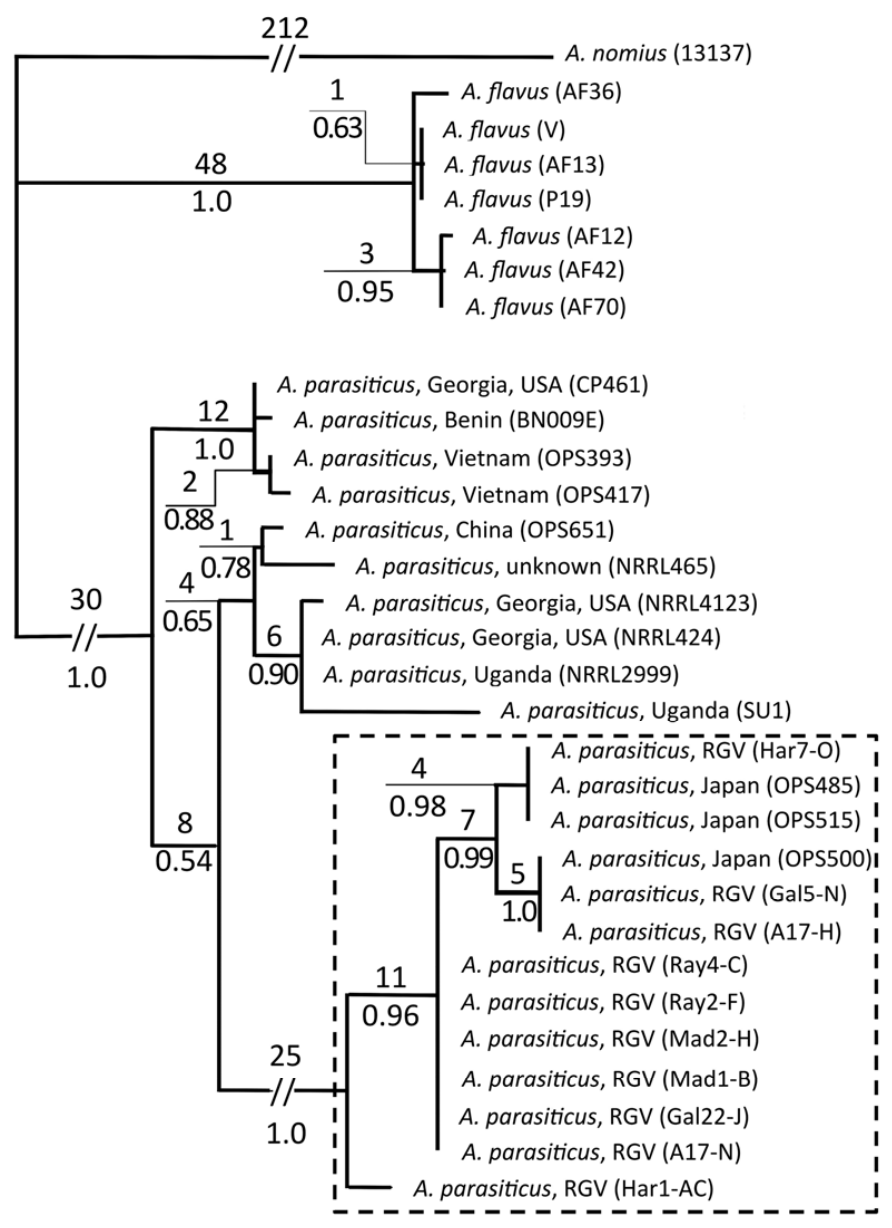

- 5 changes

Fig. 3. Aspergillus section Flavi phylogeny inferred by maximum parsimony from $2.2 \mathrm{~kb}$ of the nitrate reductase gene niaD. The single most parsimonious tree is shown, with nodes of $<80 \%$ bootstrap support collapsed. Maximumlikelihood analysis resulted in similar topology, with $91 \%$ support for the Aspergillus flavus clade and $99 \%$ for the A. parasiticus clade. Sugarcaneassociated A. parasiticus isolates were in a strongly supported clade $(88 \%$ bootstrap support), while A. parasiticus from other sources formed a clade not resolved on this tree. Numbers above branches are branch lengths proportional to the number of character changes along the branch and those below are bootstrap frequencies based on 1,000 replicates. Labels on the phylogeny are either culture collection names or laboratory working names. The tree is rooted with A. nomius (NRRL 13137) as outgroup. All A. parasiticus isolates associated with sugarcane cropping are included in the dashed box. 
absent from fields with no history of sugarcane cropping. This clearly demonstrates that sugarcane billets can be vehicles by which A. parasiticus genotypes move within agricultural areas (Table 4). The A. parasiticus lineage associated with RGV sugarcane in the current study was previously described in Japan, also on sugarcane. In agroecosystems, A. parasiticus populations differ from the contiguous, widespread, and genotypically diverse populations of A. flavus (7), in that A. parasiticus populations are discrete, often associated with a limited number of crop species, and composed of relatively fewer genotypes $(8,40,41,58)$. Diverse VCGs coexist in A. parasiticus populations, although particular VCGs may be rare in certain regions. The VCGs of each of the three A. parasiticus isolates from sugarcane cultivated in Japan were found in RGV, with $24 \%$ of $>300$ tested RGV A. parasiticus isolates belonging to one of these VCGs. In Aspergilli, membership in a VCG indicates close relatedness to other individuals within the same VCG $(4,34,57)$. It is common for a VCG to be distributed across long distances, although previous reports have shown this only across contiguous agricultural areas $(41,42)$. The current report is the first to document distribution of A. parasiticus VCGs between widely separated continents. Sugarcane cultivation may have influenced movement of these VCGs between Asia and North America. Sugarcane breeding programs rely on global germplasm collections, and U.S. programs often include Japanese accessions (67).

The association of A. parasiticus with sugarcane (Fig. 1; Table 3 ) observed in the current study resulted in sugarcane cropping changing the structure of Aspergillus section Flavi soil communities. These changes to the fungal community were more readily detected in the RGV because $A$. parasiticus does not persist long in this region in the absence of sugarcane. The lack of persistence results in A. parasiticus composing very low proportions of Aspergillus section Flavi communities when crops other than sugarcane are grown. Other crop rotations also alter structures of communities of aflatoxin-producing fungi $(34,48,49,76)$. Crop rotation effects on $A$. parasiticus may have been obscured in studies examining relationships between $A$. parasiticus and peanut production by either pooling results from 3 years (1), examining influences of crop rotations over only a single season $(33,43)$, or analyzing soils from fields with unknown cropping histories and mixed cropping regimes (37). A. parasiticus lineages associated with sugarcane are apparently dependent on that crop in the RGV. This dependence may reflect lack of competitiveness of these non-native fungi with RGV microflora and in the RGV soil environment. Similarly, non-native A. parasiticus isolates of peanut origin did not persist when applied to Arizona peanut fields (94). The extent to which Aspergillus section Flavi communities shift during crop rotation is dependent on adaptations of the constituent fungi to the soil environment, including soil chemistry, crop debris, and soil water potential (46). Processes by which specific crops favor one species, lineage, or genotype within Aspergillus section Flavi have been largely unexplored. Shifts in community compositions following rotation of sugarcane to other crops may be attributable to both plant-created environments that favor A. parasiticus and competitive differences among lineages within Aspergillus section Flavi that may be favored by other crops $(15,63)$.

\section{ACKNOWLEDGMENTS}

This research was supported by the Agricultural Research Service, United States Department of Agriculture, CRIS project 5347-42000020-00D, and Standard Cooperative Agreement 58-6435-9-398 Project 6435-42000-022-06S. We thank S. Gonzales at Rio Grande Valley Sugar Growers for his informative and accurate maps of RGV sugarcane fields, S. Sparks at SRS Farms for access to his fields and crops, and N. Glynn for useful discussions on sugarcane varietal breeding and testing.

\section{LITERATURE CITED}

1. Angle, J. S., Dunn, K. A., and Wagner, G. H. 1982. Effect of cultural practices on the soil population of Aspergillus flavus and Aspergillus parasiticus. Soil Sci. Soc. Am. J. 46:301-304.

2. Barros, G. G., Torres, A. M., Rodriguez, M. I., and Chulze, S. N. 2006. Genetic diversity within Aspergillus flavus strains isolated from peanutcropped soils in Argentina. Soil Biol. Biochem. 38:145-152.

3. Bayman, P., and Cotty, P. J. 1991. Improved media for selecting nitratenonutilizing mutants in Aspergillus flavus. Mycologia 83:311-316.

4. Bayman, P., and Cotty, P. J. 1991. Vegetative compatibility and genetic diversity in the Aspergillus flavus population of a single field. Can. J. Bot. 69:1707-1711.

5. Bayman, P., and Cotty, P. J. 1993. Genetic diversity in Aspergillus flavus: Association with aflatoxin production and morphology. Can. J. Bot. 71:23-31.

6. Blackburn, F. 1984. Sugar-cane. Tropical Agriculture. G. Wrigley, ed. Longman Group, Ltd., New York.

7. Bock, C. H., Mackey, B., and Cotty, P. J. 2004. Population dynamics of Aspergillus flavus in the air of an intensively cultivated region of southwest Arizona. Plant Pathol. 53:422-433.

8. Cardwell, K., and Cotty, P. J. 2002. Distribution of Aspergillus Section Flavi among field soils from the four agroecological zones of the Republic of Benin, West Africa. Plant Dis. 86:434-439.

9. Cotty, P. J. 1988. Simple fluorescence method for rapid estimation of aflatoxin levels in a solid culture medium. Appl. Environ. Microbiol. 54:274-276.

10. Cotty, P. J. 1989. Virulence and cultural characteristics of two Aspergillus flavus strains pathogenic on cotton. Phytopathology 79:808-814.

11. Cotty, P. J. 1994. Comparison of four media for isolation of Aspergillus flavus group fungi. Mycopathologia 125:157-162.

12. Cotty, P. J. 1994. Influence of field application of an atoxigenic strain of Aspergillus flavus on the population of A. flavus infecting cotton bolls and on the aflatoxin content of cottonseed. Phytopathology 84:1270-1277.

13. Cotty, P. J. 1997. Aflatoxin-producing potential of communities of Aspergillus section Flavi from cotton producing areas in the United States. Mycol. Res. 101:698-704.

14. Cotty, P. J. 2001. Cottonseed losses and mycotoxins. Pages 9-13 in: Compendium of Cotton Diseases T. L. Kirkpatrick, and C. S. Rothrock, eds. The American Phytopathological Society, St. Paul, MN.

15. Cotty, P. J., and Bayman, P. 1993. Competitive exclusion of a toxigenic strain of Aspergillus flavus by an atoxigenic strain. Phytopathology 83:1283-1287.

16. Cotty, P. J., Bayman, P., Egel, D.S., and Elias, K.S. 1994. Agriculture, aflatoxins and Aspergillus. Pages 1-27 in: The Genus Aspergillus from Taxonomy and Genetics to Industrial Application. K. A. Powell, A. Renwick, and J. F. Perberdy, eds. Plenum Press, New York.

17. Cotty, P. J., Probst, C., and Jaime-Garcia, R. 2008. Etiology and management of aflatoxin contamination. Pages 287-299 in: Mycotoxins: Detection Methods, Management, Public Health and Agricultural Trade. J. F. Leslie, R. Bandyopadhyay, and A. Visconti, eds. CAB International, Oxfordshire, UK.

18. Cotty, P. J., and Taylor, D. R. 2003. Influence of complementation medium composition on vegetative compatibility analyses of Aspergillus flavus. (Abstr.) Phytopathology 93:S18.

19. Couch, B., and Kohn, L. 2002. A multilocus gene genealogy concordant with host preference indicates segregation of a new species, Magnaporthe oryzae, from M. grisea. Mycologia 94:683-693.

20. Diener, U. L., Cole, R. J., Sanders, T. H., Payne, G. A., Lee, L. S., and Klich, M. A. 1987. Epidemiology of aflatoxin formation by Aspergillus flavus. Annu. Rev. Phytopathol. 25:249-270.

21. Dollear, F. G. 1969. Detoxification of aflatoxins in food and feed. Pages 360-391 in: Aflatoxin: Scientific Background, Control, and Implications. L. A. Goldblatt, ed. Academic Press, Inc., New York.

22. Dorner, J. W., Cole, R. J., and Diener, U. L. 1984. The relationship of Aspergillus flavus and Aspergillus parasiticus with reference to production of aflatoxins and cyclopiazonic acid. Mycopathologia 87:13-15.

23. Drummond, J., De Barro, P. J., and Pinnock, D. E. 1991. Field and laboratory studies on the fungus Aspergillus parasiticus, a pathogen of the pink sugarcane mealybug Saccharicoccus sacchari. Biol. Control 1:288292.

24. Egel, D. S., Cotty, P. J., and Elias, K. S. 1994. Relationships among isolates of Aspergillus sect. Flavi that vary in aflatoxin production. Phytopathology 84:906-912.

25. Ehrlich, K. C., and Cotty, P. J. 2004. An isolate of Aspergillus flavus used to reduce aflatoxin contamination in cottonseed has a defective polyketide synthase gene. Appl. Microbiol. Biotechnol. 65:473-478.

26. Ehrlich, K. C., Kobbeman, K., Montalbano, B. G., and Cotty, P. J. 2007. Aflatoxin-producing Aspergillus species from Thailand. Int. J. Food Microbiol. 114:153-159. 
27. Ehrlich, K. C., Montalbano, B. G., and Cotty, P. J. 2002. Sequence comparison of aflR from different Aspergillus species provides evidence for variability in regulation of aflatoxin production. Fungal Genet. Biol. 38:63-74.

28. Feibelman, T. P., Cotty, P. J., Doster, M. A., and Michailides, T. J. 1998. A morphologically distinct strain of Aspergillus nomius. Mycologia 90:618623.

29. Felsenstein, J. 1989. Phylogeny Inference Package (version 3.2). Cladistics 5:164-166.

30. Geiser, D., Klich, M., Frisvad, J., Peterson, S., Varga, J., and Samson, R. 2007. The current status of species recognition and identification in Aspergillus. Stud. Mycol. 59:1-10.

31. Giron, K., Lastra, L. A, Gomez, L. A. L., and Mesa, N. C. C. 2005. Observations on the biology and natural enemies of Saccahricoccus sacchari and Puluinarza pos elongata two homopterans associated with the crazy ant in sugar cane. Rev. Colomb. Entomol. 31:29-35.

32. Griffin, G. J. 1969. Fusarium oxysporum and Aspergillus flavus spore germination in the rhizosphere of peanut. Phytopathology 59:1214-1218.

33. Griffin, G. J. 1972. Conidial germination and population of Aspergillus flavus in the geocarposphere of peanut. Phytopathology 62:1387-1391.

34. Griffin, G. J., Garren, K. H., and Taylor, J. D. 1981. Influence of crop rotation and minimum tillage on the population of Aspergillus flavus group in peanut field soil. Plant Dis. 65:898-900.

35. Grubisha, L. C., and Cotty, P. J. 2010. Genetic isolation among sympatric vegetative compatibility groups of the aflatoxin-producing fungus Aspergillus flavus. Mol. Ecol. 19:269-280.

36. Hedayati, M., Pasqualotto, A., Wam, P., Bowyer, P., and Denning, D. 2007. Aspergillus flavus: human pathogen, allergen and mycotoxin producer. Microbiology 153:1677-1692.

37. Hell, K., Cardwell, K. F., and Poehling, H. M. 2003. Relationship between management practices, fungal infection and aflatoxin for stored maize in Benin. J. Phytopathol. 151:690-698.

38. Hill, R. A., Wilson, D. M., McMillian, W. W., Widstrom, N. W., Cole, R. J, Sanders, T. H., and Blankenship, P. D. 1985. Ecology of the Aspergillus flavus group and the aflatoxin formation in maize and groundnut. Pages 79-95 in: Trichothecenes and Other Mycotoxins. L. Lacey, ed. John Wiley \& Sons, New York.

39. Horn, B. W. 2003. Ecology and population biology of aflatoxigenic fungi in soil. J. Toxicol. Toxin Rev. 22:351-379.

40. Horn, B. W. 2007. Biodiversity of Aspergillus section Flavi in the United States: a review. Food Addit. Contam. 24:1088-1101.

41. Horn, B. W., and Dorner, J. W. 1998. Soil populations of Aspergillus species from section Flavi along a transect through peanut-growing regions of the United States. Mycologia 90:767-776.

42. Horn, B. W., and Dorner, J. W. 1999. Regional differences in production of aflatoxin $\mathrm{B}_{1}$ and cyclopiazonic acid by soil isolates of Aspergillus flavus along a transect within the United States. Appl. Environ. Microbiol. 65:1444-1449.

43. Horn, B. W., Greene, R. L., and Dorner, J. W. 1995. Effect of corn and peanut cultivation on soil populations of Aspergillus flavus and A. parasiticus in southwestern Georgia. Appl. Environ. Microbiol. 61:2472-2475.

44. Horn, B. W., and Greene, R. L. 1995. Vegetative compatibility within populations of Aspergillus flavus, A. parasiticus, and A. tamarii from a peanut field. Mycologia 87:324-332.

45. Jaime-Garcia, R., and Cotty, P. J. 2003. Aflatoxin contamination in commercial cottonseed in South Texas. Phytopathology 93:1190-1200.

46. Jaime-Garcia, R., and Cotty, P. J. 2004. Aspergillus flavus in soils and corncobs in south Texas: implications for management of aflatoxins in corn-cotton rotations. Plant Dis. 88:1366-1371.

47. Jaime-Garcia, R., and Cotty, P. J. 2006. Spatial distribution of Aspergillus flavus and its toxigenic strains on commercial cottonseed from South Texas and its relationship to aflatoxin contamination. Plant Pathol. 55:358-366.

48. Jaime-Garcia, R., and Cotty, P. J. 2006. Spatial relationships of soil texture and crop rotation to Aspergillus flavus community structure in South Texas. Phytopathology 96:599-607.

49. Jaime-Garcia, R., and Cotty, P. J. 2010. Effect of crop rotation and soil temperature on temporal variation of the $\mathrm{S}$ strain of Aspergillus flavus in soils of South Texas. Soil Biol. Biochem. 42:1842-1847.

50. Joffe, A. Z. 1969. Aflatoxin produced by 1,626 isolates of Aspergillus flavus from groundnut kernels and soils in Israel. Nature 221:492.

51. Klich, M. A. 2007. Aspergillus flavus: the major producer of aflatoxin. Mol. Plant Pathol. 8:713-722.

52. Klich, M. A., and Pitt, J. I. 1988. Differentiation of Aspergillus flavus from Aspergillus parasiticus and other closely related species Trans. Br. Mycol. Soc. 91:99-108.

53. Kornerup, A., and Wanscher, J. H. 1978. Methuen Handbook of Colour, $3 \mathrm{~d}$ ed. E. Methuen, London.

54. Kumeda, Y., Asao, T., Takahashi, H., and Ichinoe, M. 2003. High prevalence of B and $\mathrm{G}$ aflatoxin-producing fungi in sugarcane field soil in
Japan: heteroduplex panel analysis identifies a new genotype within Aspergillus section Flavi and Aspergillus nomius. FEMS Microbiol. Ecol. 45:229-238.

55. Kurtzman, C. P., Horn, B. W., and Hesseltine, C. W. 1987. Aspergillus nomius, a new aflatoxin-producing species related to Aspergillus flavus and Aspergillus tamarii. Antonie Leeuwenhoek 53:147-158.

56. Lee, L. S., Bennett, J. W., Goldblatt, L. A., and Lundin, R. E. 1971. Norsolorinic acid from a mutant strain of Aspergillus parasiticus. J. Am. Oil Chem. Soc. 48:93.

57. Leslie, J. F. 1993. Fungal vegetative compatibility. Annu. Rev. Phytopathol. 31:127-150.

58. Lisker, J., Michaeli, R., and Frank, Z. R. 1993. Mycotoxigenic potential of Aspergillus flavus strains isolated from groundnuts growing in Israel. Mycopathologia 122:177-183.

59. Maeda, K. 1990. Incidence and level of aflatoxin contamination in imported foods which were inspected by the official method of Japan. Proc. Jpn. Assoc. Mycotoxicol. 31:7-17.

60. Mateles, R. I., and Adye, J. C. 1965. Production of aflatoxins in submerged culture. Appl. Microbiol. 13:208-211.

61. Meagher, R. L., and Legaspi, J. C. 2003. Within-field distribution of three Homopteran species in Texas sugarcane. Southwest Entomol. 28:1-10.

62. Meagher R. L., Jr., Wilson, S. W., Blocker, H. D., Eckel, R. V., and Pfannenstiel, R. S. 1993. Homoptera associated with sugarcane fields in Texas. Fla Entomol. 73:508-514.

63. Mehl, H. L., and Cotty, P. J. 2010. Variation in competitive ability among isolates of Aspergillus flavus from different vegetative compatibility groups during maize infection. Phytopathology 100:150-159.

64. Munkacsi, A., Stoxen, S., and May, G. 2008. Ustilago maydis populations tracked maize through domestication and cultivation in the Americas. Proc. R. Soc. B 275:1037-1046.

65. Orum, T. V., Bigelow, D. M., Nelson, M. R., Howell, D. R., and Cotty, P. J. 1997. Spatial and temporal patterns of Aspergillus flavus strain composition and propagules density in Yuma County, Arizona, soils. Plant Dis. 81:911-916.

66. Park, D. L., Lee, L. S., Price, R. L., and Pohland, A. E. 1988. Review of the decontamination of aflatoxins by ammoniation: current status and regulation. J. Assoc. Off. Anal. Chem. 71:685-703.

67. Park, J. W., Solis-Gracia, N., Trevino, C., and da Silva, J. A. 2012. Exploitation of conserved intron scanning as a tool for molecular marker development in the Saccharum complex. Mol. Breed. 30:987-999.

68. Peterson, S. W. 2008. Phylogenetic analysis of Aspergillus species using DNA sequences from four loci. Mycologia 100:205-226.

69. Pildain, M. B., Vaamonde, G., and Cabral, D. 2004. Analysis of population structure of Aspergillus flavus from peanut based on vegetative compatibility, geographic origin, mycotoxin and sclerotia production. Int. J. Food Microbiol. 93:31-40.

70. Pitt, J. I., Hocking, A. D., and Glenn, D. R. 1983. An improved medium for detection of Aspergillus flavus and A. parasiticus. J. Appl. Bacteriol. 54:109-114

71. Posada, D. 2008. jModeltest: Phylogenetic model averaging. Mol. Biol. Evol. 25:1253-1256.

72. Probst, C., Callicott, K. A., and Cotty, P. J. 2012. Deadly strains of Kenyan Aspergillus are distinct from other aflatoxin producers. Eur. J. Plant Pathol. 132:419-429.

73. Probst, C., Njapau, H., and Cotty, P. J. 2007. Outbreak of an acute aflatoxicosis in Kenya in 2004: identification of the causal agent. Appl. Environ. Microbiol. 73:2762-2764.

74. Probst, C., Schulthess, F., and Cotty, P. J. 2010. Impact of Aspergillus section Flavi community structure on the development of lethal levels of aflatoxins in Kenyan maize (Zea mays). J. Appl. Microbiol. 108:600-610.

75. Rambo, G. W., Tuite, J., and Crane, P. 1974. Preharvest inoculation and infection of dent corn ears with Aspergillus flavus and A. parasiticus. Phytopathology 64:797-800.

76. Schroeder, H. W., and Boller, R. A. 1973. Aflatoxin production of species and strains of the Aspergillus flavus group isolated from field crops. Appl. Environ. Microbiol. 25:885-889.

77. Speare, A. 1912. Fungi parasitic upon insects injurious to sugar cane. Hawaiian Sugar Planters' Assoc. Exp. Stn. Bull. 12:1-62.

78. St. Leger, R. J., Screen, S. E., and Shams-Pirazadeh, B. 2000. Lack of host specialization in Aspergillus flavus. Appl. Environ. Microbiol. 66:320-324

79. Stukenbrock, E., Banke, S., Javan-Nikkhah, M., and McDonald, B. 2007. Origin and domestication of the fungal wheat pathogen Mycosphaerella graminicola via sympatric speciation. Mol. Biol. Evol. 24:398-411.

80. Suzuki, M., Narita, N., Kikuchi, Y., and Ichinoe, M. 1993. Selective isolation of Aspergillus flavus and A. parasiticus in field soils in Nansei Shoto in Japan. Proc. Jpn. Assoc. Mycotoxicol. 37:23-29.

81. Swofford, D. L. 1998. PAUP*. Phylogenetic analysis using parsimony (*and other methods). Version 4. Sinauer Associates, Sunderland, MA.

82. Tabata, S., Kamimura, H., Ibe, A., Hashimoto, H., Iida, M., Tamura, Y., 
and Nishima, T. 1993. Aflatoxin contamination in foods and foodstuffs in Tokyo: 1986-1990. J. Assoc. Off. Anal. Chem. 76:32-35.

83. Takahashi, H., Kamimura, H., and Ichinoe, M. 1999. Characterization and separation of aflatoxin-producing fungi isolated from sugarcane field in southernmost islands of Japan. Mycotoxins 49:39-43.

84. Takahashi, H., Kamimura, H., and Ichinoe, M. 2004. Distribution of aflatoxin-producing Aspergillus flavus and Aspergillus parasiticus in sugarcane fields in the Southernmost Islands of Japan. J. Food Prot. 67:90-95.

85. Tran-Dinh, N., Kennedy, I., Bui, T., and Carter, D. 2009. Survey of Vietnamese peanuts, corn and soil for the presence of Aspergillus flavus and Aspergillus parasiticus. Myopathologia 168:257-268.

86. Tseng, T. C. 1994. Recent aspects of aflatoxin research in Taiwan. J. Toxicol. Toxin Rev. 13:229-241.

87. Uichanco, L., and Villanueva, F. E. 1932. Biology of the pink mealybug of sugarcane, Triconymus sacchari (Cockerell), in the Philippines. Philipp. Agric. 21:205-276.

88. Vaamonde, G., Patriarca, A., Pinto, V. F., Comerio, R., and Degrossi, C. 2003. Variability of aflatoxin and cyclopiazonic acid production by Aspergillus section Flavi from different substrates in Argentina. Int. J. Food Microbiol. 88:79-84.

89. van Egmond, H. P. 2002. Worldwide Regulations for Mycotoxins. Pages 257-269 in: Mycotoxins and Food Safety, Advances in Experimental Medicine and Biology. J. W. DeVries, M. W. Trucksess, and L. S.
Jackson, eds. Kluwer Academic/Plenum Publishers, New York.

90. Victoria Novas, D., and Cabral, D. 2002. Association of mycotoxin and sclerotia production with compatibility groups in Aspergillus flavus from peanut in Argentina. Plant Dis. 86:215-219.

91. Wei, D. L., and Jong, S. C. 1986. Production of aflatoxins by strains of the Aspergillus flavus group maintained in ATCC. Mycopathologia 93:19-24.

92. White, T. J., Bruns, T. D., Lee, S. B., and Taylor, J. W. 1990. Amplification and direct sequencing of fungal ribosomal DNA for phylogenetics. Pages 315-322 in: PCR Protocols: A Guide to Methods and Applications. M. A. Innes, D. H. Gelfand, J. J. Sninsky, and T. J. White, eds. Academic Press, New York.

93. Williams, F. X. 1931. Family Coccidae. Pages 110-119 in: Handbook of the Insects and Other Invertebrates of Hawaiian Sugarcane Fields. F. X. Williams, ed. Experiment Station of the Hawaiian Sugar Planters' Association, Honolulu, HI.

94. Wilson, D., Holbrook, C., and Matheron, M. 1996. Aspergillus flavus and A. parasiticus used as peanut plot inoculum to study preharvest aflatoxin contamination. Proc. Am. Peanut Res. Educ. Soc. 28:30.

95. Wu, F., and Khlangwiset, P. 2010. Health economic impacts and costeffectiveness of aflatoxin reduction strategies in Africa: case studies in biocontrol and postharvest interventions. Food Addit. Contam. 27:496509. 